\title{
Sentimentos em relação à política à luz dos valores e do preconceito social
}

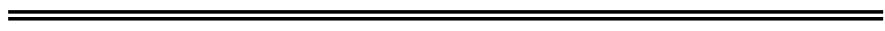 \\ Sheyla Christine Santos Fernandes ${ }^{1}$ \\ Departamento de Psicologia Universidade \\ Federal de Sergipe e Faculdade Pio Décimo²
}

\begin{abstract}
Resumo: Este estudo tem como objetivo analisar os efeitos dos valores e do preconceito social nas atitudes políticas a partir de uma perspectiva psicossociológica. Os valores são estudados em função de quatro indicadores: valores materialistas, pós-materialistas, religiosos e hedonistas; o preconceito social é abordado através da orientação à dominância social; as atitudes políticas são estudadas em duas dimensões: credibilidade nas instituições políticas e favorabilidade aos políticos. Participaram deste estudo 205 estudantes universitários de João Pessoa. Os resultados apresentam relações parciais entre estas variáveis, com a igualdade social (inverso da dominância), a valorização da religiosidade e dos valores materialistas predizendo as atitudes políticas.
\end{abstract}

Palavras-chave: valores; dominância social; atitudes políticas; comportamento sócio-político; João Pessoa

Abstract: The aim of this work is to analyse the effects of values and social prejudice on political attitudes in a psicossociological perspective. The values are analysed in four levels: materialist values, post-materialist values religious values and hedonist values; the social prejudice are analysed through the social dominance orientation; the political attitudes are studied in two dimensions: trust in political institutions and support to politicians. The research has interviewed 205 undergraduate students in João Pessoa. The results show partial relationships among those variables and social equity, the value of religiosity and post materialist values in the prediction of political attitudes.

Keywords: values; social dominance; political attitudes; social equality and socio-politic behavior; João Pessoa

1 Colaboradores: Joselí Bastos da Costa (Doutor em Psicologia Social - Docente do Departamento de Psicologia da Universidade Federal da Paraíba)/Leoncio Camino (Doutor em Psicologia Social - Docente do Departamento de Psicologia da Universidade Federal da Paraíba)/Roberto Mendoza (Mestre em Psicologia Social . Docente do Departamento de Psicologia da Universidade Federal de Campina Grande).

2 Doutoranda do Programa de Pós-Graduação em Psicologia da Universidade Federal da Bahia. 
FERNANDES, S. C. S. Sentimentos em relação à política à luz dos valores...

O sistema político vigente no Brasil abre espaço para uma série de questionamentos quanto a sua eficácia devido, principalmente, às lacunas encontradas nos usos e práticas da vida pública de nosso país (ver PAIVA, SOUZA \& LOPES, 2004).

A partir de uma perspectiva sócio-histórica, pode-se destacar no sistema político brasileiro a invasão do público pelo privado (MOREIRA LEITE, 1986; CHAUI, 1994). A reorganização do Estado patriarcal e patrimonial dos setores oligárquicos a partir do pós-guerra conduziu a uma modernização conservadora materializada em um pacto econômico e político de tipo oligárquico industrial e burocrático.

As matrizes relacionais tiveram um papel importante nessa reorganização estatal, "através de um modelo piramidal que articula uma rede de hierarquias funcionais e afetivas mantidas por intermédio da troca de favores, do mandonismo, e do prestígio político e social" (MARTIM, 1996, p. 20), ficando a autonomia do indivíduo restrita pela união e solidariedade do grupo primário. Assim, "a modernização conservadora ao reproduzir simultaneamente o tradicional e o moderno, exacerba as fases narcisistas de individualismo mercantilista e do holismo patrimonial" (MARTIM, 1996, p. 21).

Por outro lado, analisando a sociedade civil, Moisés (1992) afirmou que a sofisticação política do eleitorado (nível de urbanização, renda e escolaridade) seria responsável por um papel importante para as convicções democráticas do país, e que esta não era homogênea pois, não abarcava todas as áreas da vida política. 0 público brasileiro englobado nos extratos médios de sofisticação política (aproximadamente $50 \%$ do conjunto do eleitorado), encontrar-se-ia em posição crucial para a cristalização de uma cultura democrática, posto que são setores minimamente dotados de recursos cognitivos e informacionais indispensáveis à compreensão do funcionamento da vida política. Fatores políticos e efeitos contraditórios do processo de modernização seriam as causas da sobrevivência de arcaísmos políticos autoritários na cultura política do país, isto é, o reconhecimento dos valores democráticos ainda seria insuficiente para produzir propriamente, a estabilização definitiva da democracia.

Ademais, a partir da perspectiva da psicologia transcultural, tem se constatado que os brasileiros, segundo as dimensões dos valores culturais de Hofstede (1999), dão primazia às relações hierárquicas, à obediência e à resignação, o que faz com que sintam uma distância psicológica relativamente grande das figuras de poder. Essa distância do poder pode associar-se ao funcionamento personalizado das relações institucionais e ao estilo coronelista, predominante na dinâmica do sistema político eleitoral (MENDOZA PINTO, 1999).

Em um estudo realizado com estudantes secundários, Ferreira (1995), citado por MENDOZA PINTO (1999), observa que os estudantes tanto de escolas públicas como de escolas privadas consideram que a democracia é melhor do que 
qualquer outra forma de governo; entretanto, quase 25\% defendem que uma ditadura seria melhor em certas circunstâncias. Andrade (1996), em um estudo sobre cultura política e representações sociais, intenta captar o significado da política para os atores sociais fundamentais do nordeste brasileiro. De acordo com a autora, os setores sindicais se percebem como atores políticos e construtores da modernidade e, para eles, a política seria uma atividade nobre, o espaço público que permite lutar pela cidadania, as reformas e mudanças sociais necessárias para ascensão da modernidade. A finalidade da política seria a construção coletiva do bem-estar comum e da justiça social.

Por seu turno, os grandes e medianos proprietários rurais se percebem como os verdadeiros protagonistas da história e da vida política regional e nacional. A política seria para eles um componente identitário, na medida em que se sentem consubstanciados com ela por interesses e laços familiares. Consideram o Estado e demais instituições públicas como uma extensão do patrimônio familiar, percebendo-as como um espaço de relações e interesses privados. 0 cinismo e o utilitarismo atravessam suas representações.

Já os pequenos proprietários e os profissionais liberais, em suas representações manifestam detestar e em muitos casos temer a política. Consideram-na como uma atividade antiética por excelência. Para eles, o trabalho duro e honesto orientado em sua vida privada é o que vale. Não sentem nenhum compromisso com a vida pública, com a política. A apatia e o desencanto impregnam suas representações.

Por último, para os agricultores e pequenos camponeses em geral, o mundo da política é ininteligível, distante e alheio. Não se consideram como atores sociais e são alheios do mundo da política. A resignação e a impotência definiriam essa concepção da política.

Segundo a autora, nas representações sociais das quatro classes sociais, podem-se detectar elementos antidemocráticos, mesmo que por razões diferentes. A maioria preferiria uma democracia instrumental, que beneficiasse seus interesses setoriais ou uma ditadura de resultados, principalmente os sindicalistas e os grandes proprietários. Os outros grupos seriam indiferentes ou estariam desencantados com o sistema democrático.

De outro lado, no âmbito universitário, Echegaray (1992) constata que os critérios de moralidade, proximidade e capacidade de um candidato predominam claramente sobre os critérios político-doutrinários clássicos nas motivações que levam os estudantes a optar por una identidade política no cenário da vida nacional.

Mendoza Pinto \& Camino (2000), em um estudo sobre a configuração do espaço político entre estudantes universitários brasileiros, constatam que, apesar de avaliarem mais positivamente a democracia, a maioria desvaloriza e desqualifica os meios necessários para alcançá-la: $52 \%$ consideram a política como uma 
FERNANDES, S. C. S. Sentimentos em relação à política à luz dos valores...

atividade desprezível e $92 \%$ consideram os políticos como incompetentes, desonestos e injustos. Na mesma direção, em um estudo realizado com o Diferencial Semântico observou-se que os estudantes que estavam mais dispostos a votar consideravam a política relativamente valiosa, embora pouco satisfatória (CAMINO, 1996). Esses resultados coincidem com uma pesquisa de opinião recentemente realizada em nível nacional pela Associação de Magistrados Brasileiros $(\mathrm{AMB})^{3}$. Nela, a população também avalia muito negativamente os políticos e as instituições políticas representativas: $76 \%$ não confiam nos partidos políticos e $83 \%$ não confiam nos políticos. Ao mesmo tempo, $75 \%$ da população confiam nas Forças Armadas e na Polícia Federal.

Em meio a esse clima afetivo relativo à política e aos políticos, cabe analisar de que modo essa insatisfação com a política se expressa nos indivíduos subjetivamente. Assim, este artigo visa conhecer e analisar as atitudes acerca da política em função de dois indicadores, quais sejam: credibilidade nas instituições políticas (sistemas públicos e institucionais do país: parlamento, sistema educacional, de saúde, policial, etc.) e favorabilidade aos políticos (avaliação e confiança nos políticos). Esses indicadores são analisados a partir de duas variáveis de ordem psicossocial: os valores psicossociais e a orientação à dominância social, ambas discutidas a seguir.

\section{Valores, preconceitos e política}

Os valores psicossociais, fundamentalmente, orientam ações, escolhas, julgamentos, atitudes e explicações sociais (BEM, 1973; ROKEACH, 1979). Ao se abordar tais valores associados à política, seu papel essencial é evidenciado (BALL. ROKEACH, ROKEACH \& GRUBE, 1986; PEREIRA, CAMINO \& DA COSTA, 2004), permitindo que se analise o posicionamento político a partir da hierarquização dos valores pela sociedade, ou mesmo a partir dos sistemas ideológicos (PERISSINOTTO \& BRAUNERT, 2006).

De acordo com uma vertente psicossociológica, os valores podem ser definidos como estruturas de conhecimento socialmente elaboradas, capazes de sintetizar os elementos de um sistema simbólico amplamente compartilhado e expressar os conteúdos ideológicos que formam esse sistema, servindo, portanto de instrumento na seleção das alternativas de orientação do comportamento e refletindo o contexto sócio-cultural e as identidades sociais dos grupos e indivíduos (PEREIRA, TORRES \& BARROS, 2004).

Essa visão tem sua origem na união de duas vertentes tradicionais no estudo dos valores, a perspectiva psicológica (ROKEACH, 1968; SCHWARTZ \& BILKY,

\footnotetext{
${ }^{3}$ Consultar em: <amb.com.br, web>. Acesso em 27 set. 2007.
} 
1990) e a perspectiva sociológica (INGLEHART, 1994), sendo que a primeira parte da concepção de que os valores representam três necessidades básicas e universais da natureza humana: biológicas, de interação social estável e de sobrevivência dos grupos (necessidades individuais). Nessa, os valores podem ser definidas como concepções que o indivíduo possui sobre o desejável, concepções que, por serem transituacionais, guiam a forma como os atores sociais selecionam seu comportamento, avaliam pessoas e explicam suas ações. A segunda parte do pressuposto de que as mudanças ocorridas nas condições de produção das sociedades acompanham mudanças na hierarquia de valores e vice-versa (necessidades coletivas), os valores são entendidos como construtos essencialmente sócio-históricos.

Para a vertente psicossociológica, por seu turno, a fonte dos valores está nas produções sociais de significado, o que contempla um fenômeno de ordem social (produções sociais) vinculado a um fenômeno psicológico (elaboração de significados) (DESCHAMPS \& DEVOS, 1993) que se desenvolve a partir das lutas ideológicas pelo poder e faz parte da construção social da realidade (CAMINO, 1996).

Nesse sentido, através de diversos estudos realizados, foram identificados quatro construtos psicossociais representados por um conjunto total de vinte e quatro valores - apontados como importantes para a construção de uma sociedade ideal: Sistema materialista: engloba os valores lucro, riqueza, status e autoridade; sistema pós-materialista: representado pelos subsistemas de valores do trabalho realização profissional, responsabilidade, dedicação ao trabalho, competência; valores do bem-estar individual - alegria, amor, autorrealização, conforto; valores do bem-estar social - fraternidade, liberdade, igualdade, justiça social; sistema religioso: indicador dos valores salvação da alma, temor a Deus, religiosidade, obediência às leis de Deus; e sistema hedonista: inclui os valores vida excitante, sensualidade, prazer, sexualidade (PEREIRA et al, 2004).

A adesão dos indivíduos ou dos grupos sociais aos valores está relacionada às diversas concepções ou ideologias que possam existir sobre a natureza da sociedade. Por conseguinte, a importância dos valores nas relações políticas é ressaltada. Essa influência, independentemente da perspectiva teórica utilizada, tem sido um frequente tema de estudo (BARNEA \& SCHWARTZ, 1998; PEREIRA et al, 2004).

A orientação à dominância social, por sua vez, é um indicador do preconceito. Allport (1954), um dos pioneiros no estudo desse tema, define preconceito como uma antipatia baseada numa generalização errada e inflexível, que pode ser apenas sentida ou abertamente expressa, e pode ser dirigida a um grupo como um todo ou a um indivíduo por ser membro de tal grupo. Atualmente, o preconceito apresenta uma forte tendência a ser percebido como fenômeno social, 
FERNANDES, S. C. S. Sentimentos em relação à política à luz dos valores...

situado no contexto das relações intergrupais (TAJFEL, 1981; LIMA \& VALA, 2004) e dos processos políticos (CAMINO, DA SILVA, MACHADO \& PEREIRA, 2004). Ao situar o preconceito no campo dos fenômenos intergrupais, seu papel essencial na orientação das ações humanas torna-se inteligível.

Recentemente, foi elaborada uma abordagem que pretende englobar tanto os aspectos individuais quanto os aspectos sociais do preconceito, a Teoria da Dominância Social (TDS) (PRATTO et al, 1994; SIDANIUS \& PRATTO, 1999). Essa teoria teve forte influência de modelos da psicologia da personalidade, da psicologia social e da sociologia política e procura integrar diferentes níveis de análise no intuito de formular uma teoria mais compreensiva e completa no estudo do preconceito e da discriminação. Essa perspectiva se inicia partindo da observação básica de que todas as sociedades humanas tendem a se estruturar em sistemas de grupos baseados em hierarquias sociais.

Esses sistemas de hierarquias grupais dificilmente se modificam e possuem um alto grau de estabilidade, apesar da presença de sistemas paralelos que lutam contra as hierarquias sociais e que, em alguns casos, resultam em algumas mudanças no sentido de moderar as desigualdades sociais (PRATTO et al, 1994). Seria plausível esperar que, em sociedades democráticas, houvesse uma menor adesão às hierarquias sociais; contudo, face às novas formas de expressão do preconceito, sabe-se atualmente que essa associação não acontece como o esperado, e que os níveis de orientação à dominância social continuam presentes (FERNANDES, DA COSTA, CAMINO e MENDOZA, 2006).

Através de diversos estudos transculturais utilizando a TDS ${ }^{4}$, foram identificados três processos cumulativos, interativos e complementares responsáveis por estruturar as hierarquias sociais: 1) a discriminação individual; 2) a discriminação institucional e 3) a assimetria comportamental proveniente das assimetrias grupais. A discriminação individual se refere aos simples, diários e às vezes imperceptíveis atos de discriminação nas relações interpessoais em função de sua raça, etnia ou gênero, como por exemplo, aceitar alguém no nosso grupo, empregar ou não alguém, aprovar ou não uma pessoa, etc. Quando atos individuais desse tipo são difundidos por dias, semanas, anos, décadas e até séculos, eles contribuem para salientar e reproduzir diferenças de poder entre os grupos sociais. A discriminação institucional refere-se a regras e ações de instituições sociais que promovem, implícita ou explicitamente, distribuições assimétricas e desproporcionais de valores negativos e positivos a partir da hierarquia social instituída. Finalmente, a discriminação entre grupos se refere às formas complementares assimétricas de comportamentos sociais nas relações intergrupais

\footnotetext{
4 Para maiores detalhes ver SIDANIUS \& PRATTO, 1999.
} 
(dominância e submissão; desprezo e estima, etc.) baseados nas hierarquias sociais.

Diversos estudos demonstram que a dominância social é uma variável altamente associada às atitudes políticas e ao comportamento social como um todo, sendo os altos níveis de preconceito indicativos de altos índices de conservadorismo político e os baixos níveis relacionados à favorabilidade a uma dinâmica social igualitária (SCHMITT, BRANSCOMBE \& KAPPEN, 2003; DEAUX, REID, MARTIN \& BIKMEN, 2006). Segundo Duckitt \& Fisher (2003), as escalas utilizadas para mensurar o preconceito, como por exemplo as escalas RWA (Rightwing Autoritarianism elaborada por Altemeyer na década de 1980) e a SDO (SIDANIUS \& PRATTO, 1999; 2003), apresentam dimensões de crenças ideológicas ou atitudes sociais similares às dimensões do preconceito e das atitudes sóciopolíticas, o que sugere que são construtos altamente relacionados. Entretanto, mesmo aparecendo como variáveis estreitamente interligadas, Nishimura (2004) sugere que a existência um comportamento social conservador não está associado necessariamente às escolhas políticas dos indivíduos, pois uma série de implicações permeiam essa relação.

Nesses termos, o presente artigo tem como objetivo central investigar o papel dos valores psicossociais e da orientação à dominância social nas propensões atitudinais frente à política em uma amostra de jovens de uma capital do nordeste brasileiro.

\section{Método}

Participantes:

A pesquisa foi realizada entre os meses de outubro de 2005 e fevereiro de 2006. Participaram do estudo 205 jovens universitários de duas universidades da cidade de João Pessoa - PB, sendo a maioria do sexo feminino (77,6\%), com idades entre 16 e 30 anos (Média de 21,5 e DP de 2,54). Desses, 89,3\% eram solteiros e $48,3 \%$ se dedicavam exclusivamente aos estudos. Os sujeitos foram escolhidos em função de sua presença nas salas de aula no momento da coleta de dados.

\section{Instrumentos e procedimentos:}

Para coleta de dados foi utilizado um questionário de valores psicossociais, destinado a avaliar a estruturação dos valores sociais dos sujeitos e o grau de adesão a esses valores, composto por 24 valores, pontuados em uma escala tipo Likert, variando de 1 a 5 - 1 indicando a menor importância e 5 a maior importância. Nesse questionário, solicitou-se aos sujeitos que atribuíssem uma nota para cada valor listado de acordo com o grau de importância para a construção de uma sociedade ideal. Esse instrumento foi utilizado em diversos estudos no Brasil e tem 
FERNANDES, S. C. S. Sentimentos em relação à política à luz dos valores...

apresentado ótimos índices psicométricos (ver PEREIRA, CAMINO \& DA COSTA, 2004); 2) Também foi utilizada uma escala de Orientação à Dominância Social, escala de tipo Likert, variando de 1 a 7 - sendo 1 "totalmente em desacordo" e 7 "totalmente de acordo", composta por 16 itens, 8 referentes à igualdade (Ex.: "Seria bom que todos os grupos pudessem ser iguais") e 8 referentes à dominância (Ex.: "Os grupos superiores devem dominar os grupos inferiores"). Essa escala foi amplamente utilizada em diferentes contextos (SIDANIUS \& PRATTO, 1999) e tem se apresentado satisfatória quanto aos seus componentes psicométricos. No Brasil, foi validada em um estudo acoplado a esse e também apresentou resultado satisfatório (ver índices estatísticos na próxima seção do artigo). Finalmente, foi utilizada a escala de Atitudes Políticas, destinada a avaliar a estruturação das atitudes políticas dos sujeitos, bem como a adesão a essas atitudes. Também se trata de uma escala do tipo Likert, com as respostas variando de 1 ("totalmente em desacordo") a 7 ("totalmente de acordo"), composta por 30 itens referentes aos sentimentos dirigidos à política (Ex.: "O Parlamento (Deputados) pode ser avaliado positivamente", "Confio plenamente na Instituição Polícia", "O Sistema Público de Educação deste país pode ser avaliado positivamente"). Essa escala foi elaborada e validada em um conjunto de estudos associados a esse e mostrou ser adequada ao que se propõe (ver validação a seguir).

Os sujeitos foram abordados nas salas de aulas e, após serem dados esclarecimentos acerca da pesquisa, solicitados a participar dela. Os questionários foram aplicados coletivamente, na própria situação de sala de aula, com os sujeitos respondendo individualmente ao questionário.

\section{Descrição dos Resultados e Discussão}

Para atender ao objetivo central deste estudo, inicialmente foram realizadas as validações dos instrumentos utilizados. Para verificar a estruturação dos sistemas de valores psicossociais foi realizado um Escalamento Multidimensional (Multidimensional Scaling - MDS), técnica capaz de produzir através de distâncias euclidianas, uma interpretação das variáveis em termos de agrupamentos (TABACHNICK \& FIDELL, 1996) (Figura 1); na seqüência, realizou-se a análise dos índices de fidedignidade dos agrupamentos encontrados (os Alphas de Cronbach). Os valores se apresentaram divididos em quatro sistemas: o sistema religioso (Alpha de Cronbach $=0,76)$, representado pelos valores salvação da alma, temor a Deus, religiosidade e obediência às leis de Deus; o sistema pós-materialista (Alpha de Cronbach $=0,87$ ), representado pelos valores realização profissional, responsabilidade, dedicação ao trabalho, competência, alegria, amor, autorrealização e conforto, fraternidade, liberdade, igualdade e justiça social; o 
sistema hedonista (Alpha de Cronbach $=0,72$ ), representado pelos valores uma vida excitante, sensualidade, prazer e sexualidade e o sistema materialista (Alpha de Cronbach $=0,73)$, representado pelos valores lucro, riqueza, status e autoridade (Tabela 1).

Figura 1

Escalamento multidimensional dos sistemas de valores psicossociais

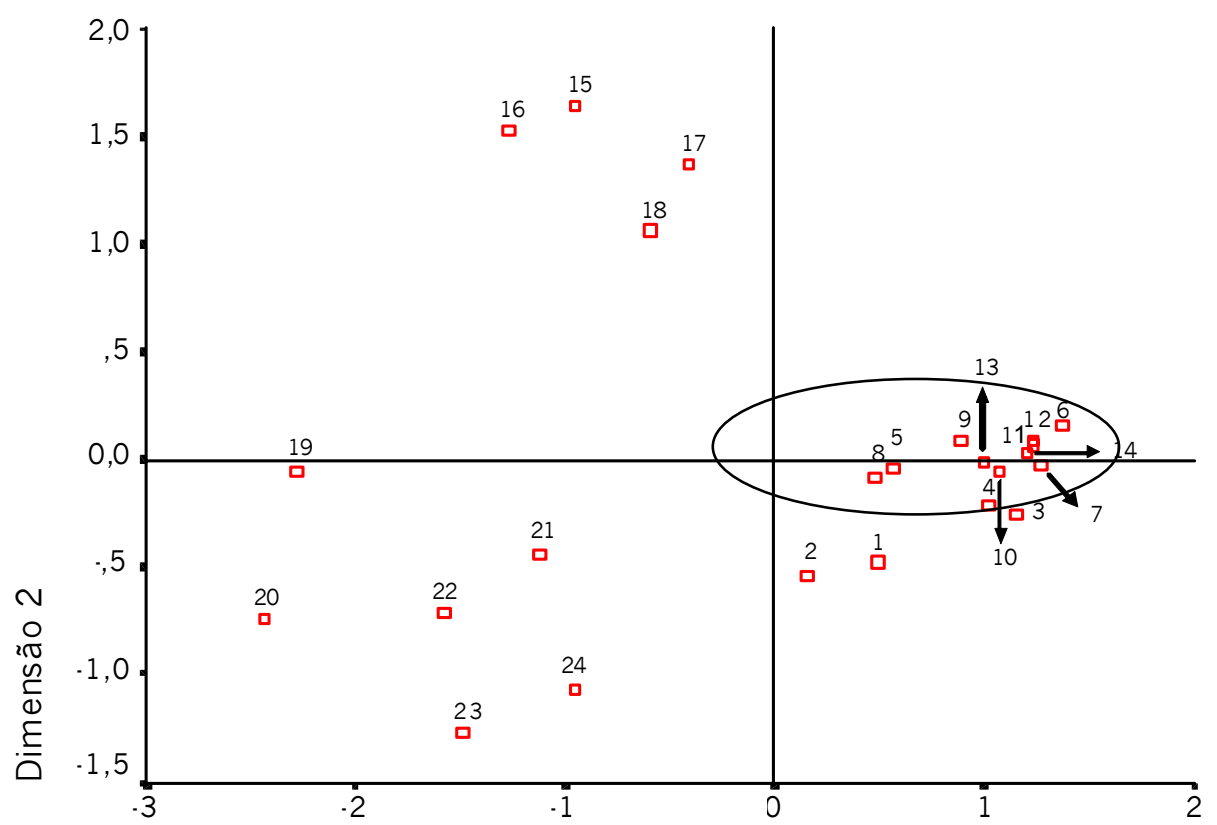

Dimensão 1

\begin{tabular}{|c|c|c|c|}
\hline \multicolumn{4}{|c|}{ Legendas } \\
\hline 1 & prazer & 9 fraternidade & 17 obediência às leis de Deus \\
\hline 2 & sexualidade & 10 autorrealização & 18 religiosidade \\
\hline 3 & realização profissional & 11 justiça social & 19 autoridade \\
\hline 4 & liberdade & 12 responsabilidade & 20 status \\
\hline & dedicação ao trabalho & 13 competência & 21 lucro \\
\hline 6 & amor & 14 alegria & 22 riqueza \\
\hline & igualdade & 15 temor a deus & 23 sensualidade \\
\hline 8 & conforto & 16 salvação da alma & 24 uma vida excitante \\
\hline
\end{tabular}

(subsistema de valores do bem-estar individual, do bem-estar social e do trabalho). 
Tabela 1

Alphas de Cronbach dos sistemas de valores psicossociais

\begin{tabular}{|l|c|}
\hline $\begin{array}{c}\text { Sistemas de Valores Psicossociais e exemplo } \\
\text { de valores entre parênteses }\end{array}$ & Alfas de Cronbach \\
\hline Religioso (salvação da alma, temor a Deus) & 0,76 \\
\hline Pós-materialista (competência, alegria, amor) & 0,87 \\
\hline Hedonista (sexualidade, prazer) & 0,72 \\
\hline Materialista (lucro, riqueza) & 0,73 \\
\hline
\end{tabular}

Para analisar a escala de orientação à dominância social foi realizada uma Análise Fatorial dos Componentes Principais com rotação Varimax. Esse procedimento permite expressar um número elevado de variáveis (itens da escala) em um pequeno número de indicadores (fatores ou dimensões) (DANCEY \& REIDY, 2006). Para que os itens estivessem todos em uma mesma direção (orientação à dominância social), os itens indicadores de igualitarismo foram invertidos (ex.: "Seria bom que todos os grupos pudessem ser iguais"; "A igualdade entre os grupos deve ser o nosso ideal"; "Todos os grupos devem ter as mesmas oportunidades na vida", estando todos a indicar a sentença oposta). Em seguida, foi analisado o índice de confiabilidade interna do fator encontrado (Alpha de Cronbach). A solução fatorial apresentou uma dimensão referente à dominância social, índice indicador do preconceito (Alpha de Cronbach =0,83) (ver Tabela 2). 


\section{Tabela 2}

\section{Análise Fatorial da Escala de Orientação à Dominância Social}

\begin{tabular}{|l|c|}
\hline \multicolumn{1}{|c|}{ Itens } & Fator \\
\hline 1- Alguns grupos têm, simplesmente, mais valor do que outros. &, 306 \\
\hline $\begin{array}{l}\text { 2- Ao fazer o que o grupo quer, às vezes é necessário usar a força contra } \\
\text { outros grupos. }\end{array}$ &, 291 \\
\hline 3. Os grupos superiores devem dominar os grupos inferiores. &, 544 \\
\hline 4- Para progredir na vida, às vezes, é necessário pisar os outros grupos. &, 508 \\
\hline $\begin{array}{l}\text { 5. Se certos grupos permanecessem em seu devido lugar, teríamos } \\
\text { menos problemas. }\end{array}$ &, 171 \\
\hline $\begin{array}{l}\text { 6- Provavelmente é bom que alguns grupos fiquem em cima e outros em } \\
\text { baixo. }\end{array}$ &, 631 \\
\hline 7- Os grupos inferiores devem permanecer em seu lugar. &, 354 \\
\hline 8- Em certas ocasiões outros grupos devem ser mantidos em seu lugar. &, 191 \\
\hline 9. Seria bom que todos os grupos pudessem ser iguais. (INVERTIDO). &, 657 \\
\hline 10. A igualdade entre os grupos deve ser o nosso ideal. (INVERTIDO). &, 718 \\
\hline $\begin{array}{l}\text { 11- Todos os grupos devem ter as mesmas oportunidades na vida. } \\
\text { (INVERTIDO). }\end{array}$ &, 795 \\
\hline $\begin{array}{l}\text { 12- Teríamos menos problemas se tratássemos os grupos diferentes de } \\
\text { forma igualitária. (INVERTIDO). }\end{array}$ &, 715 \\
\hline 13. Deveríamos aumentar a igualdade social. (INVERTIDO). &, 790 \\
\hline $\begin{array}{l}\text { 14- Devemos fazer o que for possível para igualar as condições dos } \\
\text { distintos grupos sociais. (INVERTIDO). }\end{array}$ &, 786 \\
\hline $\begin{array}{l}\text { 15. Devemo-nos esforçar para tornar os rendimentos mais iguais. } \\
\text { (INVERTIDO). }\end{array}$ &, 801 \\
\hline 16- Nenhum grupo deve dominar na sociedade. (INVERTIDO). &, 517 \\
\hline Alpha de Cronbach &, 83 \\
\hline
\end{tabular}

$\left(\mathrm{KMO}=0,82 ;\right.$ Teste de Esfericidade de Bartlett $\left.\mathrm{X}^{2}=1307,515 ; \mathrm{gl}=120 ; \mathrm{P}<, 000\right)$

Para analisar a escala de atitudes políticas, foi realizada uma análise fatorial dos componentes principais com rotação Oblimin e, em seguida, uma análise dos coeficientes de confiabilidade interna Alpha de Cronbach. Os resultados mostraram dois tipos de atitudes políticas, a credibilidade nas instituições políticas (fator 1 ) (Alpha de Cronbach $=0,75)$, relacionada a crença e aceitação das instituições políticas, como parlamento, sistema de saúde, sistema econômico, dentre outros, e favorabilidade aos políticos (Alpha de Cronbach $=0,62$ ) (fator 2), referente a avaliação e confiança nos políticos (Tabela 3). 


\section{Tabela 3 \\ Análise dos Componentes Principais, com rotação Oblimin, do conjunto de itens relativos às Atitudes Políticas}

\begin{tabular}{|l|c|c|}
\hline \multicolumn{1}{|c|}{ Itens } & Fator 1 & Fator 2 \\
\hline $\begin{array}{l}\text { O Parlamento (Deputados) pode ser avaliado } \\
\text { positivamente }\end{array}$ &, 786 & \\
\hline $\begin{array}{l}\text { O Sistema Público de Saúde deste país pode ser } \\
\text { avaliado positivamente }\end{array}$ &, 754 & \\
\hline $\begin{array}{l}\text { O Sistema Público de Educação deste país pode ser } \\
\text { avaliado positivamente }\end{array}$ &, 737 & \\
\hline $\begin{array}{l}\text { O Sistema Bancário e Financeiro deste país pode ser } \\
\text { avaliado positivamente }\end{array}$ &, 615 &, 601 \\
\hline Confio plenamente na Instituição Policial &, 505 & \\
\hline As forças armadas merecem minha confiança e respeito & &, 850 \\
\hline O poder corrompe sempre (INVERTIDO) &, 774 \\
\hline $\begin{array}{l}\text { Os políticos não se preocupam com o que pensam as } \\
\text { pessoas (INVERTIDO) }\end{array}$ & & 0,62 \\
\hline Alphas de Cronbach & 0,75 & \\
\hline
\end{tabular}

$\left(\mathrm{KMO}=0,721 ;\right.$ Teste de Esfericidade de Bartlett:: $\left.\mathrm{X}^{2}=692,815 ; \mathrm{gl}=210 ; \mathrm{P}<, 001\right)$

Após a validação dos instrumentos, foram realizadas análises de regressão múltipla pelo método stepwise para os dois tipos de atitudes políticas, considerando-se os sistemas de valores e a orientação à dominância social como variáveis explicativas (preditoras ou independentes) e os tipos de atitudes políticas como variáveis dependentes. Esse procedimento é o mais adequado para estudos de natureza exploratória, que não dispõem de modelos teóricos consistentes e apoiados em evidências empíricas acerca do relacionamento entre as variáveis, como é o caso do presente estudo (Tabelas 4 e 5).

Os valores foram abordados a partir de seus quatro sistemas (materialista, pós-materialista, religioso e hedonista), considerados pela amostra como importantes para a construção de uma sociedade ideal (média de respostas entre 3,54 e 4,55) - as respostas variavam de 1 a 7, sendo 1, "pouca importância" e 7, "muita importância". A orientação à dominância social, por sua vez, foi analisada em função de seu indicador de dominância, fortemente rejeitado pelos participantes (média $=2,17$ ). No que concerne aos indicadores das atitudes políticas, credibilidade nas instituições políticas e favorabilidade aos políticos, ambos foram rejeitados pelos universitários (média do fator $1=2,55$; média do fator $2=1,56$ ), 
mostrando que o sistema político brasileiro, apesar de ser uma democracia - e como tal é considerado como uma forma preferível de governo (KINZO, 2004) - para esses respondentes, tem alto grau de negatividade (lembrando que as respostas das escalas variavam de 1 a 7 , sendo 1 indicador de "nenhuma concordância" e 7 indicador de "total concordância" com a sentença). Pesquisas por amostragem realizadas entre os anos de 1993 e 1995 revelam dados ainda mais alarmantes, pois apontam que a percepção negativa das instituições políticas perpassa por todos os seguimentos de escolaridade, renda, idade, região, chegando a interferir nas disposições para participar na esfera pública para tomadas de decisão (MOISÉS, 1995). Dados mais atuais são consistentes com tais achados (RIBEIRO, 2007).

Tabela 4

Regressão Múltipla (Stepwise) para análise das relações entre os Sistemas de Valores, Dominância Social e a credibilidade nas instituições políticas

\begin{tabular}{|c|c|c|c|}
\hline Sistemas de Valores & $\boldsymbol{\beta}$ (Beta) & $\mathbf{t}$ & Nível de Sig. \\
\hline Hedonista & $\mathrm{x}$ & $\mathrm{x}$ & $\mathrm{x}$ \\
\hline Religioso & 0,255 & 3,010 & $\mathrm{P}<, 005$ \\
\hline Materialista & $\mathrm{x}$ & $\mathrm{x}$ & $\mathrm{x}$ \\
\hline Pós-materialista & $\mathrm{x}$ & $\mathrm{x}$ & $\mathrm{x}$ \\
\hline Dominância social & 0,355 & 4,757 & $\mathrm{P}<, 001$ \\
\hline
\end{tabular}

Tabela 5

Regressão Múltipla (Stepwise) para análise das relações entre os Sistemas de Valores, Dominância Social e favorabilidade aos políticos

\begin{tabular}{|c|c|c|c|}
\hline Sistemas de Valores & $\boldsymbol{\beta}($ Beta) & $\mathbf{t}$ & Nível de Sig. \\
\hline Hedonista & $\mathrm{X}$ & $\mathrm{x}$ & $\mathrm{x}$ \\
\hline Religioso & $\mathrm{x}$ & $\mathrm{x}$ & $\mathrm{x}$ \\
\hline Materialista & $-0,174$ & $-2,217$ & $\mathrm{P}<, 005$ \\
\hline Pós-materialista & $\mathrm{x}$ & $\mathrm{x}$ & $\mathrm{x}$ \\
\hline Dominância social & $\mathrm{x}$ & $\mathrm{x}$ & $\mathrm{x}$ \\
\hline
\end{tabular}

Como se pode perceber, foram encontradas relações explicativas parciais entre as variáveis independentes e as variáveis dependentes: a credibilidade nas instituições políticas por parte dos jovens investigados neste estudo resulta principalmente de dois aspectos: uma maior favorabilidade à dominância e uma maior adesão aos valores religiosos. Esses dados indicam que uma maior atribuição 
FERNANDES, S. C. S. Sentimentos em relação à política à luz dos valores...

de credibilidade às instituições políticas é fruto de uma menor crença na igualdade social; por sua vez, uma maior atribuição de importância aos valores religiosos leva a uma maior favorabilidade a essa atitude.

Por seu turno, a favorabilidade aos políticos foi explicada a partir dos valores materialistas, indicando que priorizar esse sistema de valores leva a uma menor confiança nos políticos. As demais variáveis não apresentaram ligações com as atitudes políticas.

O indicador de credibilidade nas instituições políticas enfatiza a crença social direcionada às instituições políticas - parlamento, sistema público de saúde, sistema bancário, sistema educacional etc. - que, por sua vez, na vida social prática de nosso país, apresenta-se de forma extremamente insatisfatória (os dados da presente pesquisa encontraram resultados condizentes com essa realidade). Diante das análises realizadas, constata-se que ser favorável ao parlamento, aos sistemas públicos de saúde, bancário, de educação etc. é uma condição antecedida por uma desfavorabilidade à igualdade (ou uma favorabilidade à dominância). Por conseguinte, aceitar e defender princípios igualitários pode também anteceder a descrença nas instituições políticas; do mesmo modo que concordar com os valores referentes à religião, como temor a Deus, obediência às leis de Deus, salvação da alma, dentre outros valores religiosos, predispõe à crença nas instituições políticas.

Por sua vez, o indicador de favorabilidade aos políticos (que enfatiza o poder dos políticos e a corrupção nele originada), também se apresentou com baixa adesão, significando que apresentar valores materialistas implica em uma avaliação negativa dos políticos. Isso é coerente com a rejeição às instituições políticas, posto que aqueles que aderem a valores materialistas de benefício imediato - status, riqueza, autoridade, lucro, etc. - pensam que os políticos, genericamente, buscam e aderem igualmente a esses mesmos valores materialistas que priorizam o benefício frente ao beneficio público. O julgamento ético-moral individual dos políticos revela que o sentimento central dessa visão da política é a resignação e o fatalismo, por um lado, e a desesperança, por outro. Essas imagem e vivência da vida política que um grupo significativo dos estudantes tem refletem as interpenetrações entre a cultura política hegemônica - a organização da instituição estatal como Estado patrimonial, que se fundamenta no clientelismo e familismo amoral - e a adesão a valores materialistas (MENDOZA PINTO \& CAMINO, 2000).

Diversos estudos com universitários brasileiros mostram que aderir aos valores de ordem pós-materialista, representados por indicadores do bem-estar individual, social e do trabalho, o que internamente acopla o valor igualdade, está associado a atitudes positivas frente à democracia; enquanto aderir ao sistema de valores religiosos e materialistas, está associado inversamente a estas atitudes 
(LIMA \& CAMINO, 1995; PEREIRA, CAMINO e DA COSTA, 2004; PEREIRA, TORRES e BARROS, 2004). Em outras palavras, ser favorável a valores como igualdade, liberdade, justiça social, autorrealização, dedicação ao trabalho, ou seja, valores que refletem a importância atribuída às questões de realização pessoal e social, implica em ser favorável aos princípios democráticos. Por outro lado, atribuir importância aos valores tradicionais e conservadores, como a obediência às leis de Deus, a religiosidade, o lucro, o poder, predizem a não aceitação dos preceitos democráticos.

Inglehart (1991) reflete acerca dessas questões de forma semelhante, defendendo que os valores de ordem pós-materialista estão relacionados a formas mais libertárias e democráticas de pensamento social, determinando modos ativos de participação política. Então, pensar na dimensão tradicional e conservadora, opositora à mudança - determinação de Schwartz e Bilsky (1990) para os valores de conservação - pode ser uma explicação plausível para as relações encontradas entre os sistemas religioso e materialista e as duas formas de atitudes políticas; quanto mais se assume uma visão tradicional e conservadora, mais se é desfavorável à democracia e às mudanças no substrato social e político.

Segundo Mendoza Pinto \& Camino (2000), aqueles estudantes mais desesperançosos com a política e que a consideram uma atividade desprezível são os que votam nos candidatos mais conservadores e populistas. Por outro lado, aqueles que a percebem como uma atividade valiosa e que mais participam, em geral, tendem a comprometer-se mais com os movimentos sociais e a eleger candidatos mais comprometidos com a mudança social.

Todavia, essa é uma relação de mão dupla e, apesar de se considerar o comportamento político mutável e complexo, resultados como esses, para serem esclarecidos e acurados, necessitam de mais estudos. As reflexões aqui apresentadas são meras iniciativas de compreensão dessa problemática, uma vez que se trata de uma amostra homogênea e sem poder de generalização. Os resultados aqui apresentados são indicativos de relações entre as variáveis do presente estudo e não necessariamente indicativos da opinião social dos jovens.

Não obstante, cabe ressaltar que o conteúdo ideológico pertinente a cada grupo social, os processos associados pelos quais esses conteúdos são elaborados e suas ações subsequentes, são substancialmente fenômenos diferentes. As normas sociais, por exemplo, possuem significados distintos dependendo da cultura em que se inserem e, por conseguinte, os sujeitos sociais apresentam escolhas diferentes em relação ao seu conteúdo e níveis de importância. Porém, pode-se considerar que, em se tratando de normas sociais, aquelas que são importantes para determinados grupos são responsáveis diretas por guiar o pensamento e o comportamento das pessoas. Embora o conteúdo ideológico varie de grupo para grupo, o processo de associação entre as variáveis sociais possui certa estabilidade. 
FERNANDES, S. C. S. Sentimentos em relação à política à luz dos valores...

\section{Considerações finais}

Se o sistema democrático brasileiro representa uma alternativa progressista, e é compreendido de forma positiva enquanto princípios gerais, na vida cotidiana, entretanto, esse modelo político não está em consonância direta com a política nacional, trazendo sérias implicações acerca de seu entendimento por parte dos cidadãos (BAQUERO, 1994; MOISÉS, 2005). O sistema político brasileiro se encontra muito aquém de atender os direitos dos cidadãos de forma equitativa. Mesmo se tratando de um país democrático, o Brasil está longe de ser um modelo de democracia pois, quando se analisa o perfil da sociedade política, o Estado, observa-se uma gama desproporcional e arbitrária de poder e privilégio nas mãos de poucos. Esse debate se apresenta consistente com os resultados apresentados neste artigo.

Tendo em vista o significado polissêmico de democracia, esperar que as representações e repertórios simbólicos acerca das atitudes políticas de jovens universitários fossem claros e isentos de quaisquer ambiguidades seria demasiado impertinente. Tal argumento salienta o conflito teórico e metodológico existente no campo da psicologia política no que concerne à fidelidade dos instrumentos mensuradores das atitudes políticas (PEREIRA et al, 2004). Isto se dá principalmente pela extrema complexidade de seu conceito; não obstante, é muito importante como campo de pesquisa, uma vez que seu papel enquanto construto social altamente associado às propensões valorativas de ordem psicossocial é inquestionável (FEATHER, 1990; PEREIRA et al, 2004). É lugar comum das ciências sociais, como um todo, compreender as estreitas relações existentes entre os indicadores sócio-culturais e as propensões atitudinais frente à política (HADDOCK, 2003; PREUHS, 2005; NELSON \& GARST, 2005; BATTISTA, 2006).

Fica aqui a certeza da necessidade de novas pesquisas considerando o cruzamento de variáveis sociais e políticas no sentido de atender às múltiplas faces do comportamento sócio-político. Essas variáveis se apresentam profundamente interligadas, sendo deveras semelhante a construção social dos significados atribuídos às mesmas pelos grupos sociais. Teoricamente, no âmbito dos sistemas de pensamento social, há uma tendência a se perceber o mundo de forma estacionária, contudo, nas práticas sociais, econômicas e políticas, essa mesma estabilidade não é observada, há uma diversidade de tendências, sendo necessário um longo tempo de práticas sociais para que uma concepção seja modificada. Isso pode ser observado na história das sociedades latino-americanas, apesar do tempo de implantação do regime democrático, ainda hoje se tem uma visão opaca do que seja democracia. O que se sabe é que, na prática, os indivíduos não têm uma idéia de eficácia dessa forma de governo, mas, teoricamente o veem como sistema ideal, o mais justo e adequado para a vida equilibrada de um país (DA COSTA, 2000; 
MOISÉS, 2005). Alguns autores argumentam que essa concepção não é consensual em função de sua complexidade sendo, portanto, bastante previsível a noção de que há uma conflituosa percepção sobre o que é certo ou errado, eficaz ou inútil no campo da política (SCHMITTER, 1997; TOURAINE, 1996). De acordo com Baquero (1994), os dados sobre o Brasil demonstram que o Estado patrimonialista precário não proporciona as bases essenciais sobre as quais a democracia pode se consolidar para além do plano jurídico formal. A "força" da democracia no Brasil, e na América Latina, estaria em seu caráter peculiar de ser uma democracia por ausência, cuja força é a inviabilidade de alternativas à vista.

Essa discussão é pertinente no contexto das interpretações provenientes das análises aqui apresentadas. Investigações realizadas com estudantes universitários considerando as relações entre os valores e o preconceito e a participação e atitudes políticas apresentam resultados equivalentes (PEREIRA et al, 2004; FERNANDES, et al, 2006). Os resultados apresentados neste artigo devem ser considerados sobretudo como uma indicação da necessidade de aprofundar e aperfeiçoar a presente investigação.

\section{Referências Bibliográficas}

ALLPORT, G.W. The nature of prejudice, Cambridge; Addison-Wesley, 1954.

ANDRADE, M. A. A. "Cultura Política e Representações Sociais. Considerações metodológicas". Política e trabalho, n¹2, p.25-39. UFPB, 1996.

BALL-ROKEACH, S.; ROKEACH, M. e GRUBE, J. W. Changing and stabilizing political behavior and beliefs. In: BALL-ROKEACH, S. e CANTOR, M. G. (Orgs.). Media, audience and social structure. Newbury Park: Sage, 1986.

BAQUERO, M. Os desafios na construção de uma cultura política democrática na América Latina: Estado e partidos políticos. In: BAQUERO, M. (Org.). Cultura política e democracia: Os desafios das sociedades contemporâneas. Porto Alegre: UFRGS, 1994.

BARNEA, M. F. e SCHWARTZ, S. H. "Values and voting". Political Psychology, n¹9, p. 17.40, 1998. 
BATTISTA, J. C. "Committee Theories and Committee Votes: Internal Committee Behavior in the California Legislature". State Politics \& Police Quarterly, $\mathrm{n}^{\circ} 1$,

p.36-51, 2006.

BEM, D. J. Convicções, atitudes e assuntos humanos. São Paulo: EPU, 1973.

CHAUÍ, M. Conformismo e resistência: aspectos da cultura popular no Brasil. São Paulo: Ed. Brasiliense, 1994.

CAMINO, L. "Uma abordagem psicossociológica no estudo do comportamento político". Psicologia e Sociedade, n 8, p.16-42, 1996.

CAMINO, L.; DA SILVA, P. e MACHADO, A. O. As novas formas de expressão do preconceito racial no Brasil: estudos exploratórios. In: LIMA, M. E. O. e PEREIRA, M. E. (Orgs.).

Estereótipos, preconceito e discriminação. Salvador. EDUFBA, 2004.

DA COSTA, J.B. Visões sociais de democracia: Um estudo psicossociológico dos significados da democracia. Tese de Doutorado não publicada, Curso de Pós-Graduação em Psicologia Social, Pontifícia Universidade Católica de São Paulo, SP. 2000.

DANCEY, C. P. e REIDY, J. Estatística sem Matemática para a Psicologia. Porto Alegre: ARTMED, 2006.

DESCHAMPS, J. C. e DEVOS, T. "Valeurs, cultures et changement". Intercultures, n¹, p. 17. 28, 1993.

DEAUX, K.; REID, A.; MARTIN, D. e BIKMEN, N. "Ideologies of Diversity and Inequality: Predicting Collective Action in Groups Varying in Ethnicity and Immigrant Status". Political Psychology, vol.27, $\mathrm{n}^{\circ} 1, \mathrm{p} .123 \cdot 146,2006$. 
DUCKITT, J. \& FISHER, K. "The impact of social threat on wordview and ideological attitudes". Political Psychology, n²4, p.199-221, 2003.

ECHEGARAY, F. "Universitarios y política en el Brasil electoral”. Revista Nueva Sociedad, n¹10, p. 26-34. México. Ed. L. Mármera, 1992.

FEATHER, N. T. Bridging the gap between values and actions: Recent applications of the expectancy-value model. In: HIGGINS, E. T. e SORRENTINO, R. M. (Orgs.). The handbook of motivation and cognition: Foundations of social behavior. New York: Guilford, 1990.

FERNANDES, S. C. S.; DA COSTA, J. B.; CAMINO, L.; MENDOZA, R. "Valores psicossociais e participação política de estudantes universitários de uma capital do nordeste brasileiro". Revista de Psicologia Política. vol.6 n¹1, p.35.64, 2006.

HADDOCK, G. "Making a Party Leader Less of a Party Member: The Impact of Ambivalence on Assimilation and Contrast Effects in Political Party Attitudes". Political Psychology, vol.24, n4, p.769.786, 2003.

HOFSTEDE, G. Cultura y organización, el software mental. Madrid: Alianza Editorial, 1999.

INGLEHART, R. El cambio cultural en las sociedades industriales avanzadas. Madrid: Siglo XXI, 1991.

. Modernización y post-modernización: La cambiante relación entre el desarrollo econômico, cambio cultural y político. In: NíCOLAS, J. D. e INGLEHART, R. (Orgs.). Tendencias mundiales de cambio en los valores sociales y políticos. Madrid: Fundesco, 1994.

KINZO, M. D. G. "Partidos, eleições e democracia no Brasil pós-1985". Revista Brasileira de Ciências Sociais, vol.19, n5, p. 23-41, 2004. 
LIMA, M. E. e CAMINO, L. A política na vida de estudantes universitários: uma análise em termos de espaço político e de valores. In: SILVA, M. J. L. (Org.). Iniciados. João Pessoa: Editora Universitária, 1995.

LIMA, M. E. O. e VALA, J. "As novas formas de expressão do preconceito e do racismo". Estudos de Psicologia. Natal, vol. 9 n 3, 2004.

MARTIM, P. H. “O amor e a Cultura da Cidadania”. In: KOURY, P. (Org.). Cultura e subjetividade. João Pessoa: Ed. Universitária, UFPB, 1996.

MENDONZA PINTO, R. Carácter Nacional: de la personalidad cultural a la percepción del sí mismo. In: MORALES, J. F. (Org.) Psicologia Social. Madrid: Ed. Prentice Hall, 1999.

MENDONZA PINTO, R. e CAMINO, L. "La configuración del espacio político. El caso de los estudiantes brasileños". Revista de Psicologia Política. n²1, p.7-30, Valencia, 2000.

MOISÉS, J. A. "Democratização e a cultura de massas no Brasil”. Lua Nova, n²6, p.5-55, 1992.

Os brasileiros e a democracia. São Paulo: Ática, 1995.

"A desconfiança nas instituições democráticas". Opinião Pública, vol.11 nº 1, p.33.63, 2005

MOREIRA LEITE, D. O caráter nacional brasileiro: história de uma ideologia. São Paulo: Ed. Pioneira, 1986.

NELSON, T. E. \& GARST, J. "Values-based Political Messages and Persuasion: Relationships among Speaker, Recipient, and Evoked Values". Political Psychology, vol.26, n4, p. 489-502, 2005. 
NISHIMURA, K. M. "Conservadorismo social: opiniões e atitudes no contexto da eleição de 2002”. Opinião Pública, vol.10, n², p.339-367, 2004.

PAIVA, D.; SOUZA, M. R. e LOPES, G. F. "As percepções sobre democracia, cidadania e direitos". Opinião Pública, vol.10, n², p.368-376, 2004.

PEREIRA, C.; CAMINO, L. e DA COSTA, J. B. "Análise fatorial confirmatória do Questionário de Valores Psicossociais - QVP24". Estudos de Psicologia. Natal, vol. 9, n³, 2004.

PEREIRA, C.; LIMA, M. E. e CAMINO, L. "A prática política: uma análise psicossociológica em termos de valores e inserção social”. In: SILVA, M. J. L. (Org.). Iniciados. João Pessoa: Editora Universitária, 1997.

PEREIRA, C.; TORRES, A. R. R. e BARROS, T. S. "Sistemas de valores e atitudes democráticas de estudantes universitários". Psicologia: Teoria e Pesquisa, vol.20, n¹, 2004.

PERISSINOTTO, R. M. e BRAUNERT, M. B. "A direita, a esquerda e a democracia: os valores políticos dos parlamentares paranaenses (1995-2002)". Opinião Pública, vol.12, n¹, p.114. 135, 2006.

PRATTO, F.; SIDANIUS, J.; STALLWORTH, L. M. e MALLE, B. F. "Social dominance orientation: a personality variable predicting social and political attitudes". Journal of Personality and Social Psychology, vol.67, n44, p.741-763, 1994.

PRATTO, F.; STALLWORTH, L. M. e SIDANIUS, J. "The gender gap: differences in political attitudes and social dominance orientation". British Journal of Social Psychology, n³9, p.49.68, 1997.

PREUHS, R. "Descriptive Representation, Legislative Leadership, and Direct Democracy: Latino Influence on English Only Laws in the States, 1984-2002". State Politics \& Police Quarterly, n5, 2005. 
RIBEIRO, E. A. "Bases da legitimidade democrática no Brasil: adesão a valores e avaliação de desempenho". Opinião Pública, vol.13, n¹, p.74-96, 2007.

ROKEACH, M. Beliefs, attitudes and values: A theory of organization and change. San Francisco: Jossey-Bass, 1968.

"The two-value model of political ideology and British politics". In: ROKEACH, M. (Org.). Understanding human values: Individual and societal. New York: Free Press, 1979.

SCHMITT, M. T.; BRANSCOMBE, N. R. e KAPPEN, D. M. "Attitudes toward group-based inequality: Social dominance or social identity?". British Journal of Social Psychology, vol.42, n², p.161-186, 2003.

SCHIMITTER, P. "Perspectivas da democracia no mundo contemporâneo: Mais liberal, préliberal ou pós-liberal?". In: GERSHMAN, S. e VIANA, M.L.W. (orgs.). A miragem da pósmodernidade:democracia e políticas no contexto da globalização. Rio de Janeiro: Fiocruz, p.31-42, 1997.

SCHWARTZ, S. H. \& BILSKY, W. "Toward a theory of the universal content structure of values: Extensions and cross-cultural replications". Journal of Personality and Social Psychology, $n^{\circ} 58$, p.878.891, 1990.

SIDANIUS, J. \& PRATTO, F. Social Dominance: An intergroup Theory of Social Hierarchy and Opression. Cambridge: Cambridge University Press, 1999.

- "Social dominance theory and the dynamics of inequality: A reply to Schmitt, Branscombe, \& Kappen and Wilson \& Liu". Journal of Social Psychology, vol.42, n², p.207. $213,2003$.

TABACHNICK, B. e FIDELL, L. S. Using Multivariate Statistics. New York: Harper Collins, 1996. 
TAJFEL, H. Human groups and social categories. New York: Cambridge University, 1981.

TOURAINE, A. O que é a democracia? Petrópolis: Vozes, 1996.

Sheyla Christine Santos Fernandes · sheylacsfernandes@msn.com

Recebido para publicação em março de 2007.

Aprovado para publicação em outubro de 2008. 